\title{
Identification and characterization of a multidomain hyperthermophilic cellulase from an archaeal enrichment
}

\author{
Joel E. Graham ${ }^{1,2, \star}$, Melinda E. Clark ${ }^{1,3, \star}$, Dana C. Nadler ${ }^{1,3}$, Sarah Huffer ${ }^{1,3}$, Harshal A. Chokhawala, ${ }^{1,3}$ \\ Sara E. Rowland ${ }^{2}$, Harvey W. Blanch ${ }^{1,3}$, Douglas S. Clark ${ }^{1,3}$ \& Frank T. Robb $b^{1,2}$
}

Despite extensive studies on microbial and enzymatic lignocellulose degradation, relatively few Archaea are known to deconstruct crystalline cellulose. Here we describe a consortium of three hyperthermophilic archaea enriched from a continental geothermal source by growth at $90^{\circ} \mathrm{C}$ on crystalline cellulose, representing the first instance of Archaea able to deconstruct lignocellulose optimally above $90^{\circ} \mathrm{C}$. Following metagenomic studies on the consortium, a $90 \mathrm{kDa}$, multidomain cellulase, annotated as a member of the TIM barrel glycosyl hydrolase superfamily, was characterized. The multidomain architecture of this protein is uncommon for hyperthermophilic endoglucanases, and two of the four domains of the enzyme have no characterized homologues. The recombinant enzyme has optimal activity at $109^{\circ} \mathrm{C}$, a halflife of $5 \mathrm{~h}$ at $100^{\circ} \mathrm{C}$, and resists denaturation in strong detergents, high-salt concentrations, and ionic liquids. Cellulases active above $100^{\circ} \mathrm{C}$ may assist in biofuel production from lignocellulosic feedstocks by hydrolysing cellulose under conditions typically employed in biomass pretreatment.

\footnotetext{
'Energy Biosciences Institute, University of California, Berkeley, California 94720, USA. ${ }^{2}$ Institute of Marine and Environmental Technology, Department of Microbiology and Immunology, University of Maryland School of Medicine, Columbus Center, 701 E. Pratt Street, Baltimore, Maryland 21202, USA. ${ }^{3}$ Department of Chemical and Biomolecular Engineering, University of California, Berkeley, California 94720, USA. * These authors contributed equally to this work. Correspondence and requests for materials should be addressed to F.T.R. (email: Frobb@som.umaryland.edu) or D.S.C. (email: clark@berkeley.edu).
} 
ellulose is the most abundant biopolymer on earth ${ }^{1}$. The hydrolysis of cellulose and its use as a microbial growth substrate is ubiquitous, as the thousands of annotated cellulases in the CAZy database attest ${ }^{2-4}$. It is therefore surprising that the Archaea, whose members have exploited most of the available carbon and energy sources on Earth, have relatively few species known to deconstruct lignocellulosic biomass ${ }^{5}$. This is especially true of the hyperthermophilic archaea. There are 35 genera of archaea with hyperthermophilic species that employ a wide range of carbon and energy sources. To date, only one hyperthermophilic archaeon, Desulfurococcus fermentans, demonstrated growth on crystalline cellulose (filter paper) at an optimum temperature of $81^{\circ} \mathrm{C}$ (ref. 6). The genome sequences of many species of hyperthermophilic archaea do encode endoglucanases, notably Pyrococcus and Sulfolobus spp.; however, cellulase genes predicted from archaeal genomes are rarely reported, and even the predicted presence of these genes does not imply an ability to grow on cellulosic substrates. Additionally, cellulases from hyperthermophiles lack identifiable cellulose binding domains, in contrast to the cellulases produced by organisms like Trichoderma reesei $i^{7}$ and Clostridium thermocellum ${ }^{8}$ that can grow using cellulosic carbon sources. These species have large and diverse inventories of glycosyl hydrolases (GHs), including multicopy hemicellulose and cellulose degrading-enzymes with various carbohydrate-binding domains. These cellulose-binding domains can be added to hyperthermophilic cellulases to increase degradation by domain addition, gene shuffling and other strategies ${ }^{1,9}$. For example, by adding a thermostable chitin-binding domain to the Pyrococcus horikoshii endoglucanase (EGph), higher activities on crystalline substrates were achieved ${ }^{10}$.

The tight structure of lignocellulose is primarily responsible for its inherent stability and strength but presents a barrier to efficient hydrolysis, a significant problem when considering lignocellulose for biofuel production. Consequently, cellulosic biomass must first be subjected to pretreatment to increase the accessible surface area, and undergo either chemical or enzymatic deconstruction to release sugars that can be subsequently fermented to biofuels. Generally, enzymatic deconstruction and hydrolysis occurs slowly under conditions typically around $50^{\circ} \mathrm{C}$ and $\mathrm{pH} 5.0$. The conditions of many pretreatment processes are much more extreme, employing high temperatures combined with low or high $\mathrm{pH}$, or steam explosion, for chemical pretreatment of feedstocks ${ }^{11}$. Strategies for commercial depolymerization of cellulose combine physicochemical pretreatment (acid or base) and enzymatic hydrolysis ${ }^{12}$. Therefore, thermophilic cellulases have been targets of research to engineer durable enzymes that can withstand harsher conditions to minimize the cost and complexity of adjusting process conditions between pretreatment and hydrolysis.

Given that no characterized hyperthermophilic archaeal species contain a minimum set of exo-, and endo-, hemicellulases required to grow on lignocellulose above $90^{\circ} \mathrm{C}$, isolating a single cellulolytic species could be problematic. Hence, we set out to reconstitute a consortium of hyperthermophiles that could deconstruct lignocellulosic biomass at $90^{\circ} \mathrm{C}$. Our hypothesis was that hyperthermophilic archaea could be enriched to grow on pulverized plant biomass and further characterized by metagenomic sequencing and enzyme characterization. Metagenomic analysis of the high temperature consortium resulted in a collection of many genes annotated as GHs, in which 12 were assigned to the closed genome of the major strain. The expression of a thermostable endoglucanase from one of these genes resulted in the identification of the most thermoactive cellulase characterized, to date. Moreover, this cellulase has a unique multidomain architecture not yet observed in hyperthermophilic cellulases.

\section{Results}

Enrichment and extraction of native protein. The enrichment strategy to identify hyperthermophiles that could degrade cellulose
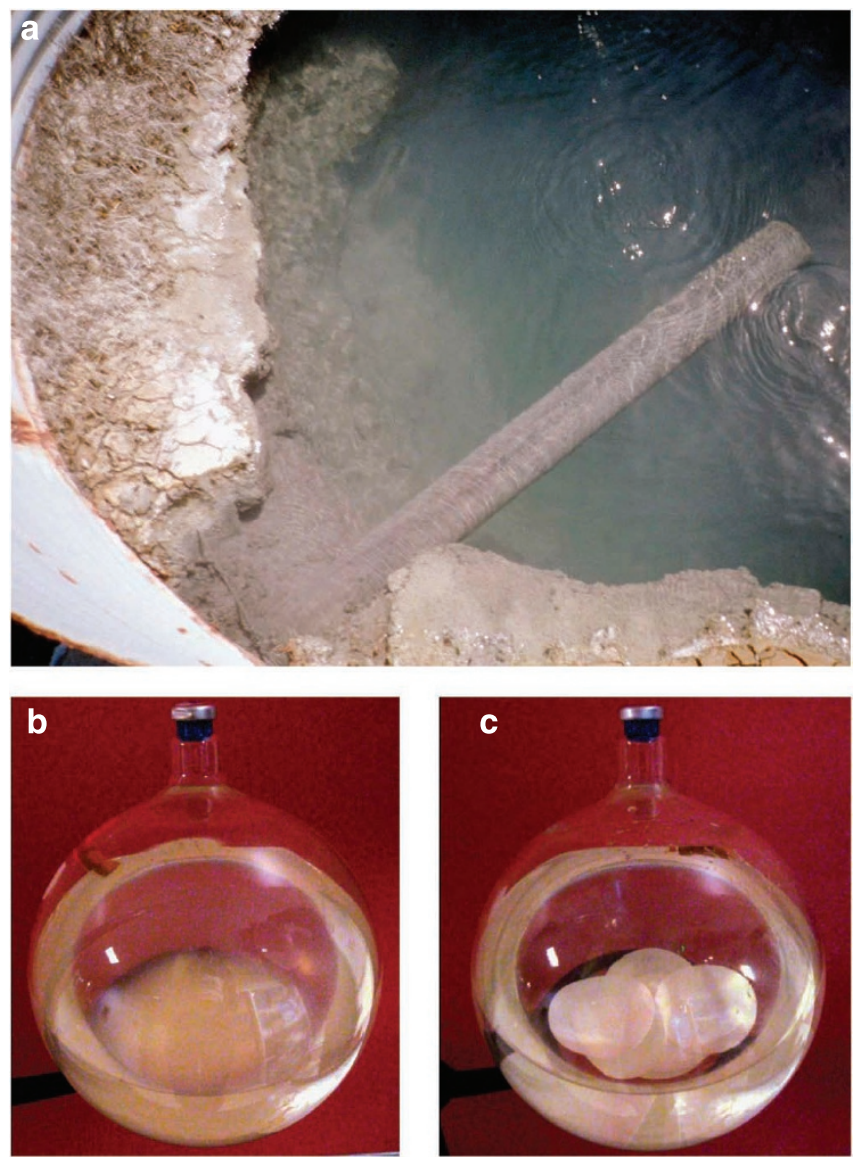

Figure 1 | Source of J1 enrichment and degradation of filter paper.

(a) Source of the J1 enrichment. A circumneutral geothermal pool at $94^{\circ} \mathrm{C}$, with a level-maintaining syphon. Sediment from the floor of this site was enriched on pulverized Miscanthus at $90^{\circ} \mathrm{C}$ and subsequently transferred to filter paper enriched media. (b) Degradation of filter paper by the $\mathrm{J} 1$ enrichment culture in a spherical $2 \mathrm{I}$ culture flask. Circular discs of Whatman No. 3 filter paper were shredded and partially dissolved after incubation for 30 days at $90^{\circ} \mathrm{C}$. (c) Control Whatman No. 3 filter paper discs. Incubation as in panel $\mathbf{b}$.

provided a strictly anaerobic three-species consortium capable of growth on Miscanthus, filter paper, Avicel (microcrystalline cellulose), and carboxymethylcellulose (CMC) at $90^{\circ} \mathrm{C}$. Figure 1a shows the collection site of the sediment that produced the enrichment, a $94^{\circ} \mathrm{C}$ geothermal pool in northern Nevada. Figure $1 \mathrm{~b}$ shows the deconstruction of Whatman No. 3 filter paper by the J1 culture in a spherical growth flask, compared with an uninoculated control (Fig. 1c). See also Supplementary Fig. S1. Repeated efforts to separate the individual species by decimal dilution and variation of growth conditions were unsuccessful. Hence, the consortium as a whole was analysed for potential cellulases of interest. Avicel was employed as the carbon source to identify the presence not only of excreted cellulases, but also to identify cellulases that are able to bind to an insoluble cellulolytic substrate. Such bound enzymes are considered to be a prerequisite for degradation of crystalline cellulose ${ }^{1,5}$. The consortium was scaled up to a 17.5-L batch culture and grown to mid-exponential phase. Cells and Avicel substrate were pelleted together by centrifugation and sonicated in buffer. The combined pellet was subjected to a series of four extractions in $0.6 \%$ $(\mathrm{w} / \mathrm{v})$ CHAPS detergent to remove insoluble membrane fractions and weakly bound proteins. Tightly bound proteins were eluted at $90^{\circ} \mathrm{C}$ $(1 \mathrm{~h})$ with two extractions in $1 \%(\mathrm{w} / \mathrm{v})$ CHAPS and $5 \%$ cellobiose. Additional protein was eluted with $1 \%$ SDS at $100^{\circ} \mathrm{C}(15 \mathrm{~min})$. The $1 \%$ 


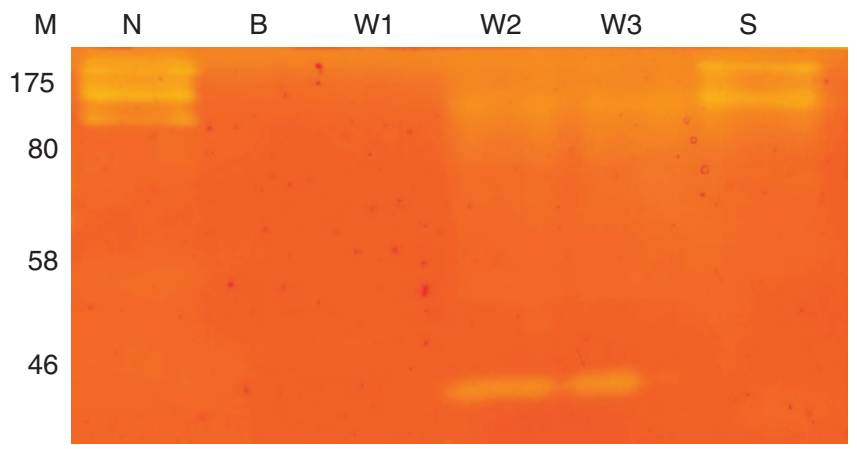

Figure 2 | Protein extraction and detection of CMCase activity. Protein extraction and detection of CMCase activity from proteins eluted from Avicel particles after deconstruction by $\mathrm{J1}$ enrichment at $90^{\circ} \mathrm{C}$ for 8 days. Image shows SDS-PAGE gradient zymogram, 10-15\% acrylamide, with $0.2 \%$ CMC embedded in gel. Lanes: M-marker, $\mathrm{N}$-native whole SDS extract, B-buffer only soluble extract, W1-0.6\% CHAPS extract, W2-1\% CHAPS 5\% Cellobiose extract \#1 (1 h incubation at $90^{\circ} \mathrm{C}$ ), W-3 $1 \%$ CHAPS $5 \%$ Cellobiose extract \#2 ( $1 \mathrm{~h}$ incubation at $90^{\circ} \mathrm{C}$ ), S-1\% SDS extract final wash $\left(15\right.$ min incubation $100^{\circ} \mathrm{C}$ ). For lanes B through S, the Avicel pellet was sonicated continuously for $2 \mathrm{~min}$ in the wash solution.

CHAPS $/ 5 \%$ cellobiose fraction showed detectable CMCase activity on zymograms. Active cellulases with apparent molecular weights of about 40 and $80 \mathrm{kDa}$ were detected (Fig. 2). Subsequent washes with $1 \%$ SDS at $100^{\circ} \mathrm{C}$ yielded the release of additional hyperstable, high-molecular weight enzymes with CMCase activity, as indicated by the activity in a smaller number of more distinct bands with apparent molecular weights of about 80 and $180 \mathrm{kDa}$ (Fig. 2). It was apparent that this consortium was producing cellulases that could bind to Avicel particles and were able to withstand boiling in 1\% SDS, abilities not yet observed in well-characterized cellulases from hyperthermophilic archaea. Therefore, metagenomics was used to identify potential cellulases from this consortium.

Sequencing and phylogenetic analysis. Pyrosequencing of the DNA extracted from cells grown on Avicel yielded 1,283,902 pyrosequencing reads with a total of $497,707,575$ bases. Assembly and dereplication resulted in $6.95 \mathrm{Mb}$ in scaffolds that differed in the read density per $\mathrm{kb}$ in the following ratio: 100:5:3. Three $16 \mathrm{~S}$ ribosomal RNA genes were identified and the closest matches to characterized organisms were Ignisphaera aggregans DSM 17230 (95\%), Pyrobaculum islandicum DSM 4184 (98\%), and Thermofilum pendens Hrk (93\%). A maximum likelihood $16 \mathrm{~S}$ rRNA gene phylogenetic tree is shown in Figure 3. Similar topology and bootstrap supported was obtained for the Neighbour-joining method (results not shown) The 16S rRNA gene from the Ignisphaera-like organism was $99 \%$ identical to $16 \mathrm{~S}$ rRNA clones from uncultured archaea from geothermal systems in both Nevada (accession number HM448083.1) and Montana (accession number EU635921.1). The Ignisphaera-like 16S rRNA (accession number JF509453) represented the dominant organism in the enrichment-based 16S rRNA clone libraries and on the large number of reads per kilobase of sequence $(\sim 300)$ for $16 \mathrm{~S}$ rRNA and the hyperthermophilic signature gene reverse gyrase, compared with read densities $(<20)$ of these two genes from the other organisms. The genome of the dominant strain has recently been closed by additional Solexa (Illumina) sequencing using the same DNA sample, and assembled into a $1.92 \mathrm{Mb}$ circular chromosome and a $21-\mathrm{kb}$ circular plasmid. The reads associated with these scaffolds amount to $85.1 \%$ of the total Solexa generated database confirming that the Ignisphaera-like strain dominates the consortium. The metagenome is currently being annotated before submission in a subsequent paper.
Identification of carbohydrate-active enzymes. Annotation analysis found a large number of GHs (37) and included 4 potential GH family 5 endoglucanases, based on automated annotation (Supplementary Table S1). Twelve of these GHs were encoded by the closed genome of the dominant strain. One predicted $\mathrm{GH}$, designated EBI-244 (accession number JF509452), was chosen for further study, because it was a potential multidomain cellulase, 842 amino acids in length, and a member of the TIM barrel glycosyl hydrolase superfamily $(\beta / \alpha)^{8}$. Large multidomain cellulases are ubiquitous amongst cellulolytic organisms but have not been previously found in hyperthermophilic archaea. The central domain of this enzyme (AA250-580) had a Pfam match $\left(E\right.$-value $\left.1 \times 10^{-12}\right)$ to the $\mathrm{GH}$ family 5 (GH5). The gene encoding EBI-244 was found on the chromosome of the dominant organism, and at $94 \mathrm{kDa}, \mathrm{EBI}-244$ was the largest of three proteins encoded on the chromosome with Pfam hits to $\mathrm{GH}$ family 5 (GH5); the others were a $43 \mathrm{kDa}$ Pfam match $\left(E\right.$-value $\left.6.3 \times 10^{-67}\right)$ and a $44 \mathrm{kDa} P$ fam match $\left(E\right.$-value $\left.8 \times 10^{-52}\right)$. According to BLASTp searches EBI-244 is a weak match to its closest apparent homologue, an uncharacterized hypothetical protein from Caldicellulosiruptor saccharolyticus (35\% identity) (Supplementary Fig. S3). The conserved central domain (AA250-580), indicated by dashed line in Supplementary Fig. S2, had only 9 significant hits (NCBI nonredundant protein database) with BLAST E-values less than $1 \times 10^{-20}$, including proteins from Herpetosiphon aurantiacus ATCC 23779, Spirochaeta thermophila DSM 6578, Spirochaeta thermophila DSM 6192, Opitutus terrae PB90-1, Chitinophaga pinensis DSM 2588, Zunongwangia profunda SM-A87, Clostridium leptum DSM 753, Victivallis vadensis ATCC BAA-548; with percent identities ranging from $25-35 \%$.

Sequence analysis of the EBI-244 enzyme. Given the deduced size of this cellulase and the possibility of multiple domains beyond the standard GH domain, Hidden Markov model (HMM) methods were pursued to predict the domain architecture for EBI-244. On the basis of the scores and alignments from HMM analysis, the EBI-244 protein is predicted to encode four structural domains, with hydrophobic and Pro/Thr-rich regions at the amino terminus (Fig. 4). The GH5 Pfam match was designated as domain 2 of EBI-244 and lies in the centre of the protein flanked by predicted structural domains on either side. Domains 1, 3 and 4 do not show similarity to any characterized domain or protein in the major databases (BLAST hits $E<0.001)$. However, several of the closest homologues of EBI244 contained domains with moderate similarity to domain 1 and 4, along with the putative catalytic domain (Supplementary Fig. S2). No sequence could be found with significant similarity to the third domain of EBI-244. The extensive predicted domain architecture is unique for GH5 family members; however, it is not unprecedented for other $\mathrm{GH}$ families (for example, $\mathrm{GH} 2$ ) $^{4}$.

The first 27 amino acids of EBI-244 likely represent a Sec-dependent signal peptide/membrane anchor (Fig. 4). The PRED-SIGNAL server, designed for archaeal proteins, predicts a trans-membrane region in EBI-244 (amino acids 7-27) with the main portion of the enzyme (after amino acid 27) in the extracellular space (reliability score: 0.975 ). This trans-membrane region was also detected with the more general prediction servers Phobius and TMHMM. Domain 1 is followed by a region of $\sim 100$ amino acids rich in Thr and Pro (Fig. 4). Thr/Pro-rich regions are generally thought to be unstructured and often serve as flexible interdomain linkers in cellulases. This region is at the $\mathrm{N}$-terminus and therefore not positioned between functional domains, but could provide a flexible linker extending from the membrane anchor. Cell surface-bound cellulases have been documented previously in the archaeal hyperthermophile P. horikoshii ${ }^{13}$.

Phylogenetic analysis was carried out using the sequence of domain 2 (GH5 match) to determine its evolutionary relationship to characterized enzymes (Fig. 5). The catalytic domain of EBI-244 


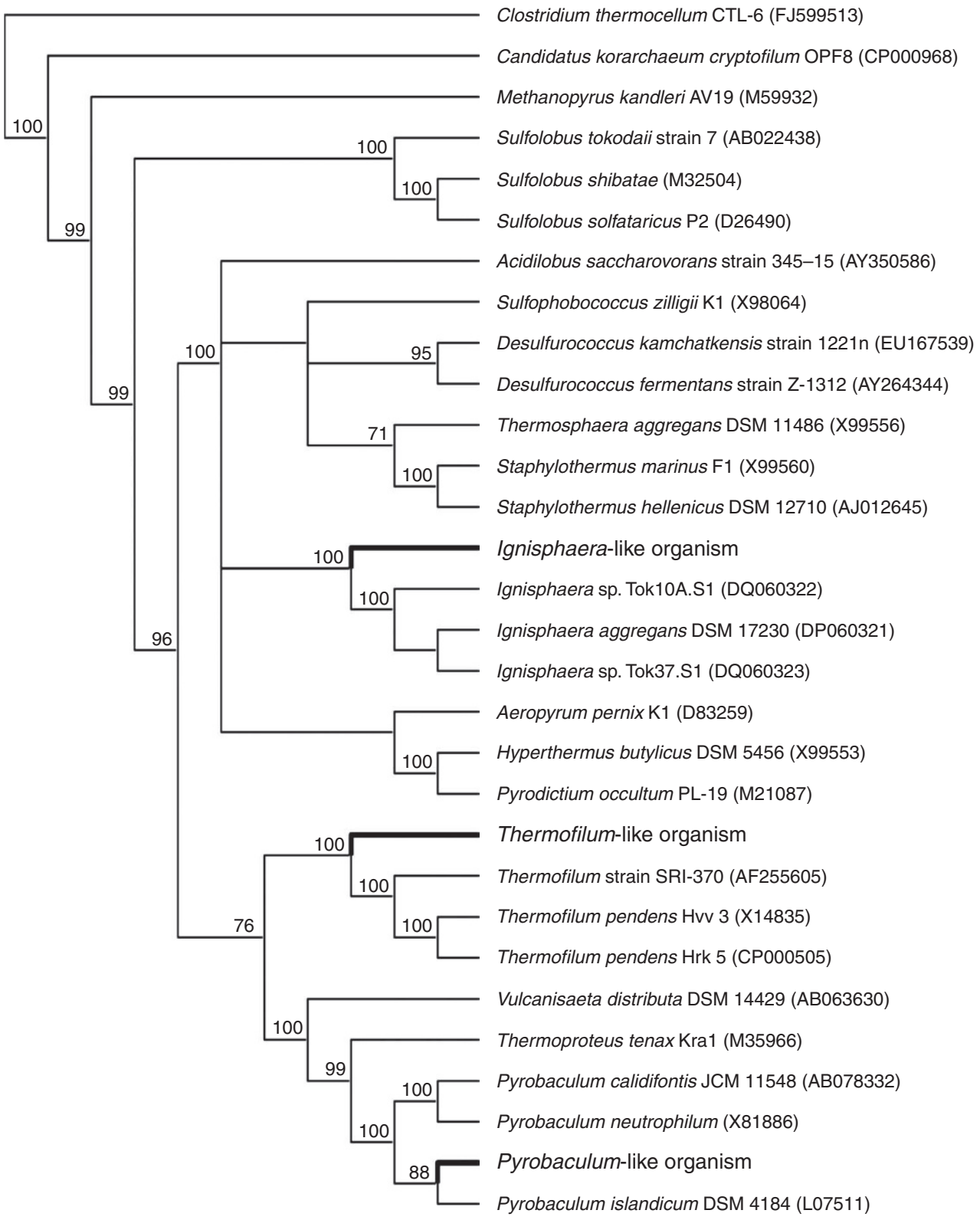

Figure 3 | Maximum likelihood phylogenetic tree. Maximum likelihood16S rRNA phylogenetic tree, showing the relationship of full-length 16S rRNAs from the three component organisms of the assembled metagenome. Branches in bold and labelled with larger type represent the three sequences from the metagenome.

clusters with a unique subset of TIM barrel sequences that show distant relationships to both GH families 5 and 42 in the calculated phylogenetic tree. In this analysis, three members of Family 30 formed a distant out-group, although they are assigned to the Clan A structural clade that includes the families GH5 and GH12. EBI-244 clusters with three characterized mannanases that have been classified in the GH5 family. The eight closest homologues of the EBI-244 catalytic domain include six that have a GH Pfam match (five from GH5, one from GH42), and two with no predictive matches (E-values shown in Fig. 5). Given this uncertain association, the unique architecture, and the diversity of the GH5 family, it is unclear whether the sequence cluster containing the EBI-244 catalytic domain is a divergent subfamily of the GH5 family or the nucleus of a new family of glycoside hydrolases.

Expression and characterization of EBI-244. EBI-244 was further characterized following its successful expression in Escherichia coli BL21 (DE3) and Rosetta cells by autoinduction ${ }^{14}$. Expression levels were relatively low, typically $\sim 20 \mu \mathrm{g} \mathrm{g}^{-1}$ cell pellet; however, the protein was obtained in soluble and active form after heating wholecell extracts to $90^{\circ} \mathrm{C}$ for $30 \mathrm{~min}$. The purified protein was shown by $\mathrm{N}$-terminal Edman sequencing to be a uniform proteolytic cleavage product truncated to Val34, determined, and, therefore, was missing the predicted signal peptide/membrane anchor (Fig. 4b). Recombinant EBI-244 showed endoglucanase activity on SDSPAGE zymograms with and without refolding steps, indicating that the protein retained activity after boiling in SDS (Supplementary Fig. S3). The enzyme was active on a range of high molecular weight carbohydrate substrates containing $\beta$-1,4-linked glucose, including CMC, Avicel, and filter paper (Table 1). The enzyme was active toward PNP-cellobioside but inactive toward PNP-glucoside (Table 1). Product analysis by fluorophore-assisted carbohydrate electrophoresis (FACE) revealed that the enzyme produces primarily cellotriose and cellotetraose from $0.33 \mathrm{mM}$ cellohexaose, with a transglycosylation reaction evident from the ladder of polymers greater than cellopentaose in lanes 2-5 (Supplementary Fig. S4). 


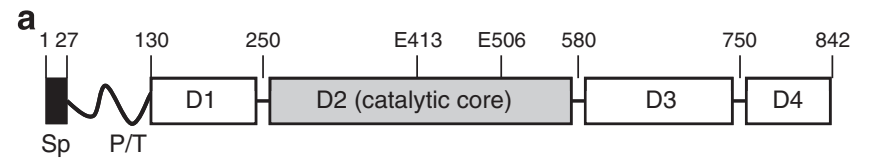

b

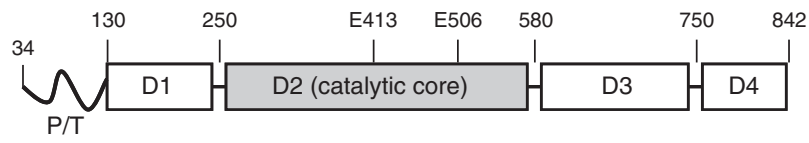

C

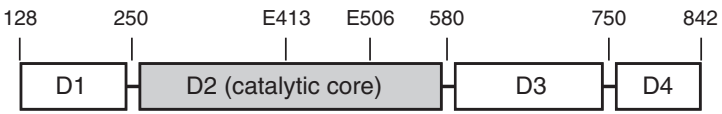

d $\begin{array}{lccc}1 & \mathrm{Sp} & 27 & \mathrm{P} / \mathrm{T} \\ \mid & \mid & \end{array}$

Figure 4 | Sequence analysis of EBI-244 enzyme. Diagrams showing predicted signal peptide/membrane anchor (Sp), Proline threonine rich low complexity region $(\mathrm{P} / \mathrm{T})$ and structural domain architecture of $\mathrm{EB} I-$ 244. This prediction is based on HMM modelling and searching of each putative domain, as well as multiple-sequence alignments of homologous sequences (Supplementary Fig. S3 is an example of a multiple alignment wherein domain boundaries are visible). Listed amino-acid positions are approximately predicted domain boundaries. (a) Diagram of predicted full-length native protein. (b) Recombinant EBI 244. (c) Recombinant EBI $244 \Delta N$. (d) Amino-acid sequence of Signal peptide and P/T region.

Truncated versions of the protein were analysed for activity on PNP-cellobiose, CMC and Avicel to determine potential functions for each domain (Supplementary Fig. S5). A truncation variant (EBI244 $\Delta 1$-127 V128M, hereafter EBI244 $\Delta$ N) lacking the Thr/Prorich region (Supplementary Fig. S5B), maintained similar activity as the full-length version on the PNP-cellbioside and CMC (data not shown). This result is expected because the threonine-/proline-rich region is predicted to be a highly flexible low-complexity region. Domains 3 and 4 do not align to experimentally characterized domains, thus it is possible that these domains act as a cellulose-binding domain or function is protein-protein interactions. Truncations removing both domains 3 and 4 or just domain 4 alone (Supplementary Fig. S5C-E) were constructed and expressed at higher levels than the full-length protein, but were inactive against all substrates (data not shown). This result indicates that domain 3, and possibly 4 as well, is required for the enzyme to remain active, possibly due to a stabilizing effect on the enzyme. Treatment of the recombinant enzyme with proteinase $\mathrm{K}$ at $50^{\circ} \mathrm{C}$ for $30 \mathrm{~min}$, resulted in a uniform $\mathrm{N}$-terminal truncation to threonine-121, determined by $\mathrm{N}$-terminal Edman degradation. The proteinase treated enzyme showed similar mobility and activity to the EBI $244 \Delta \mathrm{N}$ variant (data not shown), suggesting that the remainder of the protein forms an integrated structure that is inaccessible to proteinase $\mathrm{K}$ at $50^{\circ} \mathrm{C}$.

Figure 6 shows that EBI-244 had maximum activity at $109^{\circ} \mathrm{C}$ and negligible activity at $70^{\circ} \mathrm{C}$ when assayed against $1 \% \mathrm{CMC}$ in $50 \mathrm{mM}$ HEPPS buffer, $\mathrm{pH}$ 6.8. Similar results were observed with pretreated Avicel, Avicel, and Whatman No. 1 filter paper (data not shown). The enzyme had half-lives of $4.5 \mathrm{~h}$ in HEPPS buffer, $\mathrm{pH} 6.8$, at $100^{\circ} \mathrm{C} ; 0.57 \mathrm{~h}$ at $105^{\circ} \mathrm{C}$ in the absence of substrate (Supplementary Fig. S6); and $0.17 \mathrm{~h}$ at $108^{\circ} \mathrm{C}$ in the presence of microcrystalline cellulose (0.5\% Avicel) (Supplementary Fig. S7). Differential scanning calorimetry of the enzyme (Fig. 5, inset) showed a bifurcated transition with $2 T_{\mathrm{m}}$ 's of 111 and $113^{\circ} \mathrm{C}$. EBI- 244 retained activity over a broad $\mathrm{pH}$ range, similar to other characterized GH5s (refs 15,16 ), from $\mathrm{pH} 3.5$ to $\mathrm{pH} 8.0$ at $95^{\circ} \mathrm{C}$, with an optimum of pH 5.5 (Supplementary Fig. S8). Ionic detergents, including SDS, had little effect on enzyme activity or stability and both non-ionic and non-denaturing ionic detergents such as CHAPS-stimulated activity (Supplementary Fig. S9).

Given that EBI-244 remained active under high $(\mathrm{NaCl})$ to near-saturating $(\mathrm{KCl})$ salt conditions (Supplementary Fig. S10), its activity was measured in the presence of the ionic liquids 1 , 3-dimethylimidazolium dimethyl phosphate (DMIM)DMP) and 1-ethyl-3-methylimidazole acetate ((EMIM)OAc), which could potentially be used to pretreat substrates like Miscanthus ${ }^{17}$. The concentrations tested, 25 and $50 \%(\mathrm{v} / \mathrm{v})$, are well above the expected residual ionic liquid of $10-15 \%$ that may be carried over after pretreatment ${ }^{18}$. CMCase activity was demonstrated in zymograms, incubated at $90^{\circ} \mathrm{C}$ in $25 \%(\mathrm{v} / \mathrm{v})$ of either ionic liquid ( $\left.\mathrm{pH} 6.8\right)$ (data not shown). EBI-244 remained stable and active at $90^{\circ} \mathrm{C}$ in $25 \%$ [DMIM]DMP (Supplementary Fig. S10). Interestingly, in these assays, the enzyme's $T_{\text {opt }}$ decreased in the presence of ionic liquids (Supplementary Fig. S11), suggesting that denaturing effects of the ionic liquids may stimulate activity at lower temperatures at which the enzyme would otherwise be inactive.

\section{Discussion}

Growing solely on crystalline cellulose is apparently not a simple feat, and the list of characterized organisms that grow on crystalline cellulose around $90^{\circ} \mathrm{C}$ is sparse. The list includes the archaeon $D$. fermentans (up to $89^{\circ} \mathrm{C}$ ), and the bacterium C. bescii ${ }^{6,19}$. C. bescii was recently reported to grow at up to $90^{\circ} \mathrm{C}$ on Avicel, filter paper and switchgrass ${ }^{19}$. To increase the likelihood of discovering thermophilic cellulases, we targeted microbial consortia, rather than single isolates, that would grow around $100^{\circ} \mathrm{C}$ on refractory crystalline forms of cellulose. This approach, a compromise between environmental metagenomics and classical microbial isolation, resulted in the discovery of a limited archaeal enrichment capable of growing on crystalline cellulose at $90^{\circ} \mathrm{C}$, and maximally at $94^{\circ} \mathrm{C}$. Although the consortium enriched on Avicel PH-101 consisted of three strains, the closest characterized organism to the dominant member is related to I. aggregans DSM17230 (ref. 20), representing a divergent new species of this genus. Although similarity to characterized strains is low, environmental samples from hotsprings in Nevada and Montana have yielded 16SrDNA sequences with as close as 99\% identity sequence comparison suggesting that this species may be widespread in continental geothermal systems. Single isolates from this enrichment were not possible to obtain, which was not surprising given past difficulties in isolating Ignisphaera spp. ${ }^{20}$ It is possible that the diverse enzymes needed for lignocellulose utilization (cellulases, cellulose binding domains, CBMs, xylanases, and cellobiohydrolases) do not allow for the survival of a single isolated hyperthermophilic Archaeon given the compact genome size typically found within these organisms $(<2 \mathrm{Mb})$. For example, the genome of the dominant organism in our enrichment is $1.94 \mathrm{Mb}$ compared with $2.93 \mathrm{Mb}$ for C. bescii. This limitation may give rise to more symbiotic relationships during cellulolytic growth at high temperatures. No archaeal cellulases from $D$. fermentans have been characterized to date but recently secretome and genome analysis showed several GHs coded by the bacterium $C$. bescii ${ }^{21}$. Given the limited success in finding single hyperthermophiles that can grow on crystalline cellulose, the discovery of hyperthermophilic cellulases may necessitate the broader application of enrichment driven metagenomics.

The metagenome of our $90^{\circ} \mathrm{C}$ consortium showed a multidomain cellulase with a high Thr/Pro N-terminal region, a core TIM barrel glycosyl hydrolase superfamily catalytic domain with low similarity to known cellulases, and uncharacterized amino-terminal domains. The cellulase, designated EBI-244, appears to be membrane-bound, a characteristic also observed for the cellulase in $P$. horikoshii ${ }^{13}$, which may be necessary to maintain the enzyme and/or the products generated in close proximity to the organism. It may also be less energy intensive to maintain enzymes on the cell surface, which would be beneficial, given the recalcitrance of the carbon. 


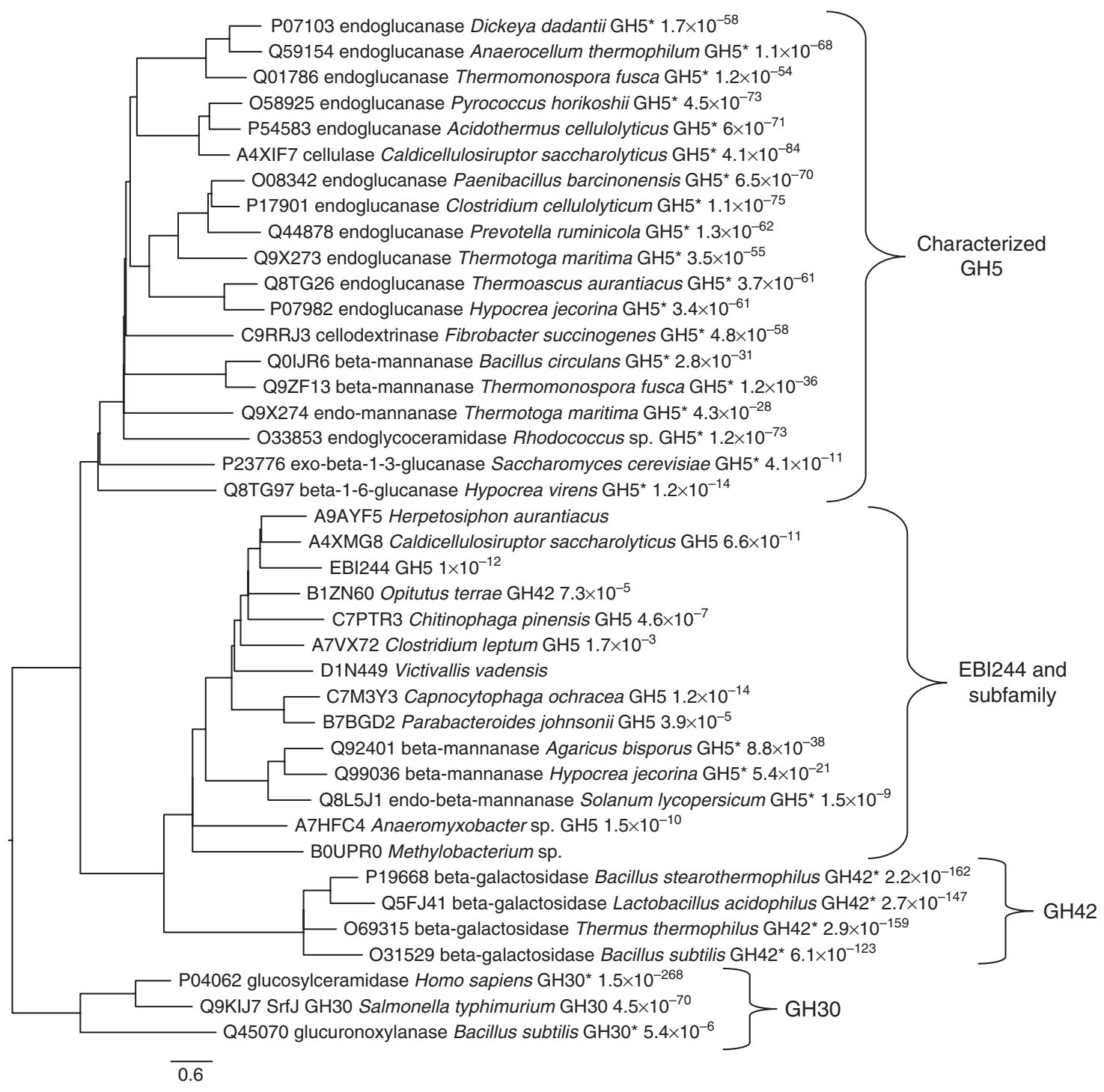

Figure 5 | Phylogeny of the EBI-244 protein putative catalytic domain. A phylogenetic tree was produced showing the relationship of the catalytic domain of EBI-244 to the closest characterized GH families. Tree entry information: Uniprot identifier; enzyme function (if known); organism name; Pfam hit GH family (asterisk indicated characterized enzyme in CAZy database); and E-value (where no GH is listed there was no significant Pfam hit).

The catalytic domain of EBI-244 aligns distantly with a unique group of enzymes that are mostly uncharacterized (Fig. 5). The enzymes within this group come from a variety of eukaryotic and prokaryotic organisms, including Agaricus bisporus (mushroom), Anaeromyxobacter (iron-reducing bacterium), Solanum lycopersicum (tomato plant), and Capnocytophaga ochracea (Gram-negative bacterial opportunistic pathogen). It is interesting to note that the mannanases within this subgroup all originate from eukaryotes. The bacterial and archaeal organisms from this list were isolated from diverse environments including subsurface and rice paddy sediments, the human GI tract, human faeces, the slime coat of freshwater algae, the phyllosphere or roots of plants, pine litter, and thermal springs. Although most of these organisms inhabit environments that may contain a cellulolytic substrate, most cannot use cellulose as a carbon source. Some can use cellobiose, but C. saccharolyticus and the Ignisphaera-like strain reported here are the only two that are known to be able to grow on crystalline cellulose as a sole carbon source. Among this disparate group they are also the only thermophiles. This broad diversity begs the question of why such
Table 1| The specific activity of EBI 244 endoglucanase on different substrates.

\begin{tabular}{lcc} 
Substrate & Activity & Error (\%) \\
\hline pNP-cellobioside & $178^{\star}$ & 1 \\
CMC & $138^{\star}$ & 5 \\
Barley Glucan & $518^{\star}$ & 7 \\
Lichenan & $6,296 \dagger$ & 5 \\
Avicel & $1,241 \dagger$ & 3 \\
IL-Avicel & $8,261 \uparrow$ & 2 \\
IL-Miscanthus & $1,002 \uparrow$ & 4 \\
IL-Cornstover & $1,318 \dagger$ & 2 \\
AFEX Cornstover & $89 \dagger$ & 5 \\
Xylan & NA & - \\
Mannan & NA & - \\
\hline${ }^{*} \mu$ mol GE per $\mu$ mol enzyme min ${ }^{-1}$. & & \\
† $\mu$ mol GE per $\mu$ mol enzyme $15 \mathrm{~h}^{-1}$. GE stands for glucose equivalents. Substrates pretreated \\
with lonic Liquid (IL) and Ammonia Fiber Expansion (AFEX) are indicated. NA indicates no \\
measurable activity.
\end{tabular}




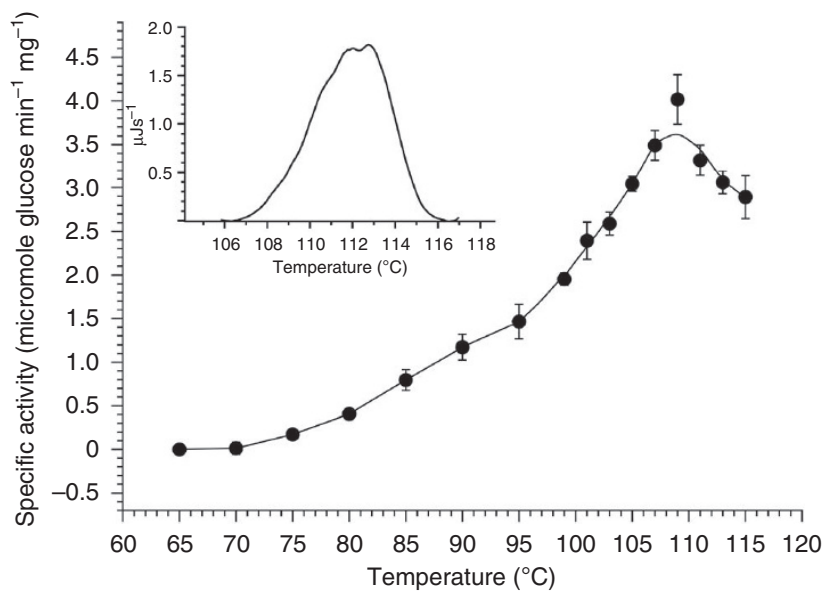

Figure 6 | Temperature profile of the EBI-244 enzyme. The temperature versus activity profile was measured by 20 -min assay in $1 \%$ CMC in $25 \mathrm{mM}$ sodium acetate buffer, $\mathrm{pH}$ 6.0. The products were detected by dinitrosalicylic acid reducing sugar assay and normalized to a cellobiose standard. Error for this experiment was below 15\%. Inset: Differential scanning calorimetry results of enzyme from 102 to $116^{\circ} \mathrm{C}$. A dual $T_{\mathrm{m}}$ was observed at 111.5 and $113^{\circ} \mathrm{C}$.

diverse organisms have a distantly similar enzyme whereas so few organisms have one at all. It may be that the ancestral gene diverged from a manannase GH5 subfamily gene that was transferred horizontally from a eukaryote. Alternately, improved metagenomic sampling of geothermal sources could show that this cellulase clade may in fact not be rare at all, but rather is found predominantly in consortia described here.

The domains composing the rest of EBI-244 generate a unique architecture for a GH5 enzyme. The truncation results indicate that deletions at the $\mathrm{N}$ terminus do not alter the catalytic function of the enzyme or its stability, but that domain 3 (and possibly domain 4 as well) is necessary for the catalytic domain to be functional. It is possible that these domains interact with the substrate, much like the internal cellulose-binding domain in the E4 endocellulase from Thermomonospora fusca, which not only contributes to binding but also to activity ${ }^{22}$. However, the inactivity of the C-terminal-truncated enzyme renders it difficult to determine whether these domains associate with the substrate or if their role is solely structural.

Recombinantly expressed EBI-244 has unique properties. These include hyperthermostability (optimal activity at $109^{\circ} \mathrm{C}, T_{\mathrm{m}}$ of $113^{\circ} \mathrm{C}$ ), halotolerance, resistance to ionic and non-ionic detergents, and activity in ionic liquids. The broad resilience of EBI-244 may be due to its hyperthermophilic character, not unlike other GH5s from extremophilic organisms. Endoglucanases from $P$. horikoshii (EGph) and Pyrococcus furiosus had optimum temperatures of 95 and $100{ }^{\circ} \mathrm{C}$, respectively ${ }^{23,24}$. The hyperthermophilic endoglucanases from Thermatoga maritima (Tma Cel5A) and EGph exhibited stability in the presence of ionic liquids ${ }^{25}$. Recombinant Cel5A retains $44 \%$ of its activity in $15 \%$ [EMIM] OAc after $15 \mathrm{~h}$ whereas Pho EG retained $70 \%$ (refs. 25,26). A GH5 cellulase designated CelA 10 that is $83 \%$ similar to Cel5B from Cellovibrio japonicus, a halophile, remained active in $30 \%(\mathrm{v} / \mathrm{v})$ of six different ionic liquids tested and also retained $50 \%$ and $30 \%$ activity in $4 \mathrm{M} \mathrm{NaCl}$ and $4 \mathrm{M} \mathrm{KCl}$, respectively ${ }^{26}$. EBI-244 showed a similar trend of tolerance with these results from other extremophilic GH5s.

In summary, this study describes the first archaeal consortium that can grow optimally, using crystalline cellulose as a carbon source at temperatures above $90^{\circ} \mathrm{C}$. Furthermore, several potential cellulases have been identified and one has been further characterized. EBI-244 is the most thermotolerant endoglucanase reported to date, and it has a unique domain architecture compared with all other hyperthermophilic GHs as well as to GH family 5 enzymes. EBI-244 also has the hallmarks of an enzyme that could enable the consortium to carry out disassembly and hydrolysis of lignocellulose, providing a new benchmark for microbial degradation of refractory lignocellulose biomass in extreme environments.

\begin{abstract}
Methods
Source material. Sediment was removed from a pool with allochthonous decomposing wood at a site named Great Boiling Springs at $40^{\circ} 3945.1 \mathrm{~N}, 119^{\circ} 21$ 59.0 W, near Gerlach, Nevada (Fig. 1a). A small glass jar (4 oz) was filled with sediment, topped off with spring water and sealed hot. Samples were transported on ice and long-term sample storage was carried out in anaerobic jars at $4{ }^{\circ} \mathrm{C}$.
\end{abstract}

Enrichment. Strictly anaerobic microbial enrichment $(90 \mathrm{ml})$ was with sediment inoculated into minimal salts medium based on DSMZ medium \#516, with low yeast extract $\left(0.2 \mathrm{~g} \mathrm{l}^{-1}\right)$ and the pulverized Miscanthus gigas (a grass, $80 \mu \mathrm{M}$ particle size) as the primary carbon and energy source. After 3 weeks at $90^{\circ} \mathrm{C}$, a secondary enrichment with microcrystalline cellulose (Avicel Ph-101 Fluka, Ireland) was set up. The enrichment obtained on Avicel was transferred to medium containing strips of Whatman No. 3 filter paper as a sole carbon source and incubated at $90^{\circ} \mathrm{C}$ until decomposition of the filter paper was observed.

DNA extraction and sequencing. Standard protocols for extraction of high molecular weight DNA from the Avicel enrichment using the CTAB method were followed ${ }^{27}$. Sequencing was done via Roche 454 titanium. Initial automated assembly was by Newbler. Automated annotation was done using a local MANATEE database and nr BLAST. In addition, further annotation was conducted through the MicrobesOnline Comparative Genomics Database. The MicrobesOnline annotation consisted of protein coding prediction using CRITICA and Glimmer3 followed by annotation using the VIMSS genome pipeline (DOE Genomes to life Program) composed of all publicly available sequence databases.

Mass spectrometry. Tandem mass spectrometry of peptides was conducted at the California Institute for Quantitative Biosciences Proteomics/Mass Spectrometry Core Facility.

Identification of cellulase-encoding genes and gene synthesis. The gene encoding the protein characterized herein was chosen because of its homology to the cellulase superfamily/glycoside hydrolase family 5 EC 3.2.1.4 as well as its similarity to a hypothetical protein from C. saccharolyticus. The gene/protein was given the designations ebi-244/EBI-244. The gene was synthesized de novo by Genscript A second version of the gene, codon optimized for expression in E. coli, was synthesized by DNA 2.0.

Sequence and phylogenetic analysis. Potential homologues were gathered with PSI-BLAST ${ }^{28}$ using each putative domain of EBI-244 as the query sequence against the $\mathrm{nr}$ protein sequence database. The SAM software package ${ }^{29}$ was used to build HMM's, score the potential homologue sequences, and create alignments for building new models. This method was used iteratively with each putative domain to build more general models in order to detect distant homologues. Jalview ${ }^{30}$ was used to view and edit multiple sequence alignments. The resulting alignments allowed for approximate domain boundary determination.

The phylogenetic tree was built using the SATCHMO-JS server ${ }^{31}$. All sequences were aligned with the Expresso server ${ }^{32}$ to trim sequences down to only the structur ally related GH domain. All characterized GH family 5 and GH family 42 sequences in the CAZy database ${ }^{4}$ were used initially to compare with EBI-244 and its closest homologues. The size of the tree was reduced by using Jalview's remove-redundancy function, thereby also preserving the diversity of each family. The Pfam web server ${ }^{2}$ was used to score the sequences against Pfam HMM models of the GH families.

Protein expression. Expression of the recombinant EBI-244 protein was routinely carried out by the autoinduction ${ }^{14}$. The enzyme was expressed in E. coli Rosetta cells (Invitrogen). Cells were incubated with shaking at 20 or $25^{\circ} \mathrm{C}$ for 48 or $36 \mathrm{~h}$, respectively. Expression was optimized in 11 shake flask cultures, and subsequently scaled up to 17.51 in a New Brunswick Bioflow IV fermentor. Cells were grown to an optical desnsity (OD) $550 \mathrm{~nm}$ of approximately 2.5-3.0 and collected by centrifugation at $6,000 \mathrm{~g}$. Cells were lysed by French Pressure in $50 \mathrm{mM}$ sodium phosphate buffer or $50 \mathrm{mM}$ HEPPS buffer and incubated for $30 \mathrm{~min}$ at $90^{\circ} \mathrm{C}$. Denatured host proteins were removed by centrifugation at $8,000 \mathrm{~g}$ for $15 \mathrm{~min}$ followed by $100,000 \mathrm{~g}$ for $30 \mathrm{~min}$. The cleared supernatant, representing a partially purified soluble fraction, was used immediately for assays or purification.

\section{Enzyme purification}

Native protein(s): The enrichment grown on Avicel PH-101 in a 201 specialized fermentor was collectedted by centrifugation. The pellet, principally Avicel, was resuspended in cold $\left(0^{\circ} \mathrm{C}\right) 50 \mathrm{mM}$ HEPPS buffer $\mathrm{pH} 6.8$ at a rate of $10 \mathrm{~g}$ pellet per $40 \mathrm{ml}$ and sonicated for $2 \mathrm{~min}$ using a Fisher Scientific 550 Sonic Dismembranator. 
Resuspension consisted continuous sonication for $2 \mathrm{~min}$. The mixture was centrifuged $\left(4^{\circ} \mathrm{C}\right)$ for $15 \mathrm{~min}$ at $8,500 \mathrm{~g}$ and the supernatant was decanted. The pellet was then resuspended in HEPPS buffer and centrifugation was repeated and the supernatant decanted. The pellet was resuspended in $50 \mathrm{mM} \mathrm{HEPPS} / 0.6 \%$ CHAPS detergent $\left(25^{\circ} \mathrm{C}\right)$, followed by centrifugation. The $0.6 \% \mathrm{CHAPS}$ wash was repeated three more times and all $0.6 \%$ CHAPS fractions were pooled. The remaining washed pellet was resuspended in HEPPS buffer with 1\% CHAPS and $5 \%$ cellobiose and incubated for $1 \mathrm{~h}$ at $90^{\circ} \mathrm{C}$, cooled to approximately ambient temperature $\left(25^{\circ} \mathrm{C}\right)$ and centrifuged. This wash step was repeated. The remaining pellet was resuspended in $1 \%$ SDS at $100^{\circ} \mathrm{C}$ for $15 \mathrm{~min}$. The CHAPS cellobiose fraction and the final fractions contained proteins including active cellulases that were presumably tightly bound to partly digested cellulose fibrils. Total activity in cell and pellet fractions was assayed by sonicating $\times 2$ SDS-PAGE loading buffer (w/v, 2.5\% SDS, $10 \%$ glycerol $60 \mathrm{mM}$ Tris/ $\mathrm{HCl} \mathrm{pH}$ 6.8, $0.5 \mathrm{mM}$ EDTA, $0.36 \mathrm{M}$ 2-mercaptoethanol, $0.005 \%$ bromphenol blue) and incubated at $65^{\circ} \mathrm{C}$ for $30 \mathrm{~min}$ before electrophoresis.

Recombinant protein: Clarified supernatants after heat treatment were fractionated by ammonium sulfate precipitation then buffer-exchanged on a PES membrane centrifugal concentrator (Sartorius). The protein sample was fractionated on a butyl-hydrophobic interaction column (GE Healthcare), and eluted with a linear gradient from 0.5 to $0 \mathrm{M}$ ammonium sulfate in $50 \mathrm{mM}$ sodium phosphate $\mathrm{pH}$ 6.8. Active fractions were pooled, and eluted from Q Sepharose fast flow column with a $\mathrm{KCl}$ gradient from $0 \mathrm{M}$ to $500 \mathrm{mM}$.

Zymogram visualization of cellulase activity. Zymogram gels were made as standard $8 \%$ SDS-PAGE gels excepting that $0.25 \%$ medium viscosity CMC was incorporated into the gel. In the case of gradient gels, the gels were 10-15\% acrylamide and contained 0.20\% CMC. Standard SDS-PAGE protocols and loading buffer were used, however samples were kept at $20^{\circ} \mathrm{C}$ and were not boiled before loading. The gel was agitated for $30 \mathrm{~min}$ in $50 \mathrm{mM}$ Tris buffer $\mathrm{pH} 6.8$ with $2 \%$ Triton X-100, followed by $30 \mathrm{~min}$ in $50 \mathrm{mM}$ Tris buffer $\mathrm{pH} 6.8$ incubated in $50 \mathrm{mM}$ potassium phosphate $\mathrm{pH} 6.8$ or $50 \mathrm{mM}$ HEPPS buffer, $\mathrm{pH} 6.8$ for $3 \mathrm{~h}$ at $90^{\circ} \mathrm{C}$, and stained with $0.5 \%$ Congo Red for $40 \mathrm{~min}$. Destaining with $1 \mathrm{M}$ Tris buffer $\mathrm{pH} 6.8$ for $15 \mathrm{~min}$ at room temperature was followed by setting the dye in $1 \mathrm{M} \mathrm{MgCl}_{2}$.

Cellulase assays. Dinitrosalicylic acid reagent was used to detect reducing sugars at OD. Results were calibrated to standard solutions of cellobiose. Assays on CMC Avicel, ionic liquid pretreated Avicel and Whatman No. 1 filter paper were carried out in $50 \mathrm{mM}$ potassium phosphate $\mathrm{pH} 6.8$ or $50 \mathrm{mM}$ sodium acetate $\mathrm{pH} 5.5$. Assays with high concentrations of salts or ionic liquids were carried out in phosphate buffer. Assays were usually conducted in $100 \mu \mathrm{l}$ at $T<98^{\circ} \mathrm{C}$ in a thermocycler with a heated lid. Assays covering a temperature range of $100-130^{\circ} \mathrm{C}$ were conducted in a silicone oil bath in silanized, heat-sealed capillary tubes ( $20 \mu \mathrm{l}$ final volume).

Alternative substrate assays. Assays on alternative substrates described in Table 1 were done as follows Pretreated substrates were treated as previously described ${ }^{9}$. All cellulolytic assays for insoluble substrates were carried out in quadruplicate in a final volume of $70 \mu \mathrm{l}$ containing $1 \%(\mathrm{w} / \mathrm{v})$ substrate (glucan loading), $0.2 \mu \mathrm{M}$ of the EBI-244 and $100 \mathrm{mM}$ sodium acetate buffer, $\mathrm{pH} 5.5$ at $90^{\circ} \mathrm{C}$ in a thermal cycler (Applied Biosystems). Cellulase activities were measured for Avicel, Lichenan, AFEX pretreated corn stover, ionic-liquid pretreated avicel (IL-Avicel), Miscanthus (IL-Miscanthus), and corn stover (IL-corn stover). The mixtures were incubated at $90^{\circ} \mathrm{C}$ for $15 \mathrm{~h}$ after which they were cooled to $4{ }^{\circ} \mathrm{C}$ before measuring the amount of soluble reducing sugar released using the glucose oxidase-peroxidase assay as previously described ${ }^{9}$.

Paranitrophenol-labelled glycosides. The chromogenic substrates 4-nitrophenyl beta-D-glucopyranoside and 4-nitrophenyl-beta-D-cellobioside were utilized in $100 \mathrm{mM}$ sodium acetate buffer. Sodium acetate buffer containing 4-nitrophenol was used as a standard. To compare activity at various $\mathrm{pH}$ levels, the following buffers were used at a buffer strength of $50 \mathrm{mM}$ : pH 2.5-5.5 acetate/acetic acid, pH 6.5 MES, pH 7.5-8.5 HEPPS, pH 9.5-10.5 CAPS. All assays on PNP-substrates and standards were adjusted with an equal volume of $100 \mathrm{mM}$ sodium hydroxide before recording the absorbance at $410 \mathrm{~nm}$.

Fluorophore assisted carbohydrate electrophoresis (FACE). Assays to determine the time course of product generation from cellopentaose and cellohexaose were performed as previously described ${ }^{33}$.

\section{References}

1. Bayer, E., Chanzy, H., Lamed, R. \& Shoham, Y. Cellulose, cellulases and cellulosomes. Curr. Opin. Struct. Biol. 8, 548-557 (1998).

2. Finn, R. D. et al. The pfam protein families database. Nucleic Acids Res. 38, D211-D222 (2010).

3. Henrissat, B. \& Coutinho, P. Classification of glycoside hydrolases and glycosyltransferases from hyperthermophiles. Methods Enzymol. 330, 183-201 (2001)
4. Cantarel, B. et al. The Carbohydrate-Active EnZymes database (CAZy): an expert resource for glycogenomics. Nucleic Acids Res. 37, D233-D238 (2009)

5. Blumer-Schuette, S. E., Kataeva, I., Westpheling, J., Adams, M. W. W. \& Kelly, R. M. Extremely thermophilic microorganisms for biomass conversion: status and prospects. Curr. Opin. Biotechnol. 19, 210-217 (2008).

6. Perevolova, A. et al. Desulfurococcus fermentans sp nov., a novel hyperthermophilic archaeon from a Kamchatka hot spring, an emended description of the genus Desulfurococcus. Int. J. Syst. Evol. Micro. 55, 995-999 (2005).

7. Martinez, D. et al. Genome sequencing and analysis of the biomass-degrading fungus Trichoderma reesei (syn. Hypocrea jecorina). Nat. Biotechnol. 26, 553-560 (2008).

8. Kurokawa, J. et al. Clostridium thermocellum cellulase CelT, a family 9 endoglucanase without an Ig-like domain or family $3 \mathrm{c}$ carbohydrate-binding module. Appl. Microbiol. Biotechnol. 59, 455-461 (2002).

9. Kim, T., Chokhawala, H., Nadler, D., Blanch, H. \& Clark, D. Binding modules alter the activity of chimeric cellulases: effects of biomass pretreatment and enzyme source. Biotechnol. Bioeng. 107, 601-611 (2010).

10. Kang, H., Uegaki, K., Fukada, H. \& Ishikawa, K. Improvement of the activity of the hyperthermophilic cellulase from Pyrococcus horikoshii. Extremophiles 11, 251-256 (2007).

11. Kim, J., Lee, Y. \& Torget, R. Cellulose hydrolysis under extremely low sulfuric acid and high-temperature conditions. Appl. Biochem. Biotechnol. 91-93, 331-340 (2001)

12. Kumar, P., Barrett, D. M., Delwiche, M. J. \& Stroeve, P. Methods for pretreatment of lignocellulosic biomass for efficient hydrolysis and biofuel production. Ind. Eng. Chem. Res. 48, 3713-3729 (2009).

13. Kashima, Y., Mori, K., Fukada, H. \& Ishikawa, K. Analysis of the function of a hyperthermophilic endoglucanase from Pyrococcus horikoshii that hydrolyzes crystalline cellulose. Extremophiles 9, 37-43 (2005).

14. Studier, F. W. Protein production by auto-induction in high-density shaking cultures. Protein Expres. Purif. 41, 207-234 (2005).

15. Bischoff, K. M., Liu, S. \& Hughes, S. R. Cloning and characterization of a recombinant family 5 endoglucanase from Bacillus licheniformis strain B-41361. Process Biochem. 42, 1150-1154 (2007).

16. Liu, J. et al. Cloning and functional characterization of a novel endobeta-1,4-glucanase gene from a soil-derived metagenomic library. Appl. Microbiol. Biotechnol. 89, 1083-1092 (2011).

17. Shill, K. et al. Ionic liquid pretreatment of cellulosic biomass: enzymatic hydrolysis and ionic liquid recycle. Biotechnol. Bioeng. 108, 511-520 (2011).

18. Engel, P., Mladenov, R., Wulfhorst, H., Jager, G. \& Spiess, A. C. Point by point analysis: how ionic liquid affects the enzymatic hydrolysis of native and modified cellulose. Green Chem. 12, 1959-1966 (2010).

19. Yang, S. J. et al. Classification of Anaerocellum thermophilum strain DSM 6725 as Caldicellulosiruptor bescii sp. nov. Int. J. Syst. Evol. Biol. 60, 2011-2015 (2010).

20. Niederburger, T., Gotz, D., McDonald, I., Ronimus, R. \& Morgan, H. Ignisphaera aggregans gen. nov., sp. nov., a novel hyperthermophilic crenarchaeote isolated from hot springs in Rotorua and Tokaanu, New Zealand. Int. J. Syst. Evol. Biol. 56, 956-971 (2006).

21. Blumer-Schuette, S. E., Lewis, D. L. \& Kelly, R. M. Phylogenetic, microbiological, and glycoside hydrolase diversities within the extremely thermophilic, plant biomass-degrading genus Caldicellulosiruptor. Appl. Environ. Microbiol. 76, 8084-8092 (2010).

22. Irwin, D. et al. Roles of the catalytic domain and two cellulose binding domains of Thermomonospora fusca E4 in cellulose hydrolysis. J. Bacteriol. 180, 1709-1714 (1998).

23. Ando, S., Ishida, H., Kosugi, Y. \& Ishikawa, K. Hyperthermostable endoglucanase from Pyrococcus horikoshii. Appl. Environ. Microbiol. 68, 430-433 (2002)

24. Bauer, M. et al. An endoglucanase, EglA, from the hyperthermophilic archaeon Pyrococcus furiosus hydrolyzes beta-1,4 bonds in mixed-linkage $(1 \rightarrow 3)$, $(1 \rightarrow 4)$-beta-D-glucans and cellulose. J. Bacteriol. 181, 284-290 (1999).

25. Datta, S. et al. Ionic liquid tolerant hyperthermophilic cellulases for biomass pretreatment and hydrolysis. Green Chem. 12, 338-345 (2010).

26. Pottkamper, J. et al. Applying metagenomics for the identification of bacterial cellulases that are stable in ionic liquids. Green Chem. 11, 957-965 (2009).

27. Ausubel, F. M. et al. Current Protocols in Molecular Biology, Vol 2 (John Wiley \& Sons, 1994).

28. Johnson, M., Zaretskaya, I., Raytselis, Y., Merezhuk, Y., McGinnis, S. \& Madden, T. L. NCBI BLAST: a better web interface. Nucleic Acids Res. 36, W5-W9 (2008).

29. Karplus, K., Barrett, C. \& Hughey, R. Hidden markov models for detecting remote protein homologies. Bioinformatics 14, 846-856 (1998).

30. Waterhouse, A. M., Procter, J. B., Martin, D. M., Clamp, M. \& Barton, G. J. Jalview version 2-a multiple sequence alignment editor and analysis workbench. Bioinformatics 25, 1189-1191 (2009).

31. Hagopian, R. et al. SATCHMO-JS: a webserver for simultaneous protein multiple sequence alignment and phylogenetic tree construction. Nucleic Acids Res. 38, W29-W34 (2010).

32. Armougom, F. et al. Expresso: automatic incorporation of structural information in multiple sequence alignments using $3 \mathrm{~d}$-coffee. Nucleic Acids Res. 34, W604-W608 (2006). 
33. Gao, N. Fluorophore-assisted carbohydrate electrophoresis: a sensitive and accurate method for the direct analysis of dolichol pyrophosphate-linked oligosaccharides in cell cultures and tissues. Methods. 35, 323-327 (2005).

\section{Acknowledgements}

This research was supported by the Energy Biosciences Institute. We are grateful to Brian Hedlund and Jeremy Dodsworth, (University of Nevada, Las Vegas) for sharing information on the sampling site, on the basis of their long-term observations of the area. We acknowledge Peipei Zhang for technical assistance with zymograms and cellulase assays, Paul Wolski for helpful advice concerning enzyme activity assays in the presence of ionic liquids, and Poonam Saija and Craig Dana for stimulating discussions. We are grateful to Nadya Pavlova for assistance with the FACE analysis, and Adam Arkin's laboratory group, especially Keith Keller, for help with annotation of the metagenome.

\section{Author contributions}

F.T.R., D.S.C., J.E.G. and H.W.B. conceived and designed the experiments. J.E.G. and F.T.R. collected the samples. M.E.C. and J.E.G. created the enrichments and carried out metagenomic analysis. J.E.G., F.T.R. and S.E.R. conducted recombinant protein expression large-scale growth and purification of cellulases. H.A.C. and S.E.R. carried out product and substrate analysis and enzyme stability studies. D.C.N. and J.E.G. carried out in silico analysis of protein sequences. J.E.G., M.E.G., F.T.R., D.S.C. and H.W.B. wrote the paper.

\section{Additional information}

Acccession codes: The sequence data have been deposited under accession codes JF509452 and JF509453 in the GeneBank non-redundant protein and non-redundant nucleotide databases respectively.

Supplementary Information accompanies this paper at http://www.nature.com/ naturecommunications

Competing financial interests: The authors declare no competing financial interests. Reprints and permission information is available online at http://npg.nature.com/ reprintsandpermissions/

How to cite this article: Graham, J. E. et al. Identification and characterization of a multidomain hyperthermophilic cellulase from an archaeal enrichment. Nat. Commun. 2:375 doi: 10.1038/ncomms1373 (2011). 